\title{
Investigation on Indoor Environment of Camping Tent
}

\author{
Jingbo Liu ${ }^{1, a}$, Yingni Jiang ${ }^{2, \mathrm{~b}}$ and Xiao $\mathrm{Ma}^{3, \mathrm{c}^{*}}$ \\ ${ }^{1}$ Graduate Management Department, Logistics University of PAP. Tianjin, China \\ ${ }^{2,3}$ Architecture Engineering Department, Logistics University of PAP. Tianjin, China \\ a568818102@qq.com, bjyingnii@sina.com, 33227297@qq.com
}

Keywords: Tent; Indoor Environment; Investigation; Improvement

\begin{abstract}
There are often some problems, such as hot and humid air, crowded air, on the indoor environment of tents. Based on the above problems, the writer makes a thorough investigation on the use of the tents for the people. The result indicates that the camping tent is far lower than fixed barracks on various indoor environment, such as closure, thermal environment, acoustical and optical environment, sanitary condition and facilities. The main factor which interferes with good rest is the muggy environment.
\end{abstract}

\section{Introduction}

There are many kinds of camping tents, which are mostly erected by the frames and the tarpaulin. They are weak in closed lax, unstable, poor ventilation, poor insulation and others. There are some studies analysis and improvement on the environment of tent currently, which are mainly concentrated in the improvement of heating mode [1-2], natural ventilation improving [3], structure upgrading[4-7], spray coating, watering and aluminum foil [8]. Even the transformation methods are varied, the general method to improve personal satisfaction is not much. Most study only used in the field of scientific research, cannot be applied actually. In order to upgrade tent equipment and improve the camping conditions, the research group asked the people lived in the camping tents with questionnaires and interviews to get objective first-hand information on the living experience. It puts forward the reform proposal as a starting point and provides reference for the study later.

\section{Investigation Overview}

Research Content. In order to understand the environment of camping tent and to know the personal feelings in the tent, the research group have asked the people, who have ever lived in tent, to get the objective evaluation of the camping tent. The question was about the changes of the physical and psychological aspects. Finding the main influence factors to do some research, providing ideas for the upgrading of the tent.

Research Methods. Questionnaire survey and interviews are used as the method of the research. The group firstly interviewed the actual feeling in the tent, making a record, and then designed the questionnaire according to the contents of the interview. These can help the statistic results more accurate and more universal.

Questionnaire Design. Based on the intuitive feeling of the people in the tent, the people were asked to the content of activities in the tent, sleep quality, physical condition and the subjective feelings of the tent. There are 16 questions in the questionnaire, and the types of questions are multiple-choice; including radio and multi selection.

\section{The Results of Research}

Analysis of Activities within the Tent. Tent is an important place for the rest of people to have a rest, so that it is necessary to make a question to understand the activities and the proportion of the people in the tent. It is an important prerequisite for the analysis of the security capacity of the tent. Fig. 1 for the people's activities in the tent of the project statistics. 


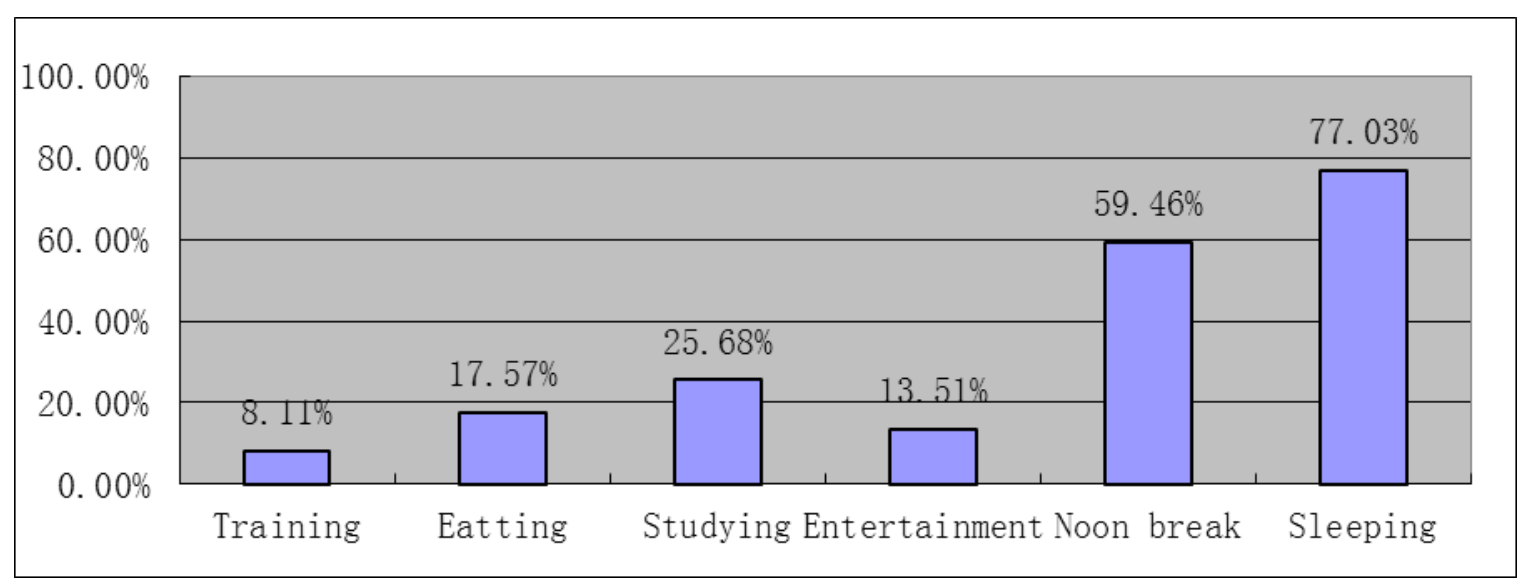

Figure 1. Statistics of the people's activities in camping tent

It can be seen from Fig. 1 that nearly $80 \%$ people sleeping in the evening with the tent and nearly $60 \%$ people have a noon break after lunch in the tent; study ranks third, accounting for more than $25.7 \%$ applicants. The result shows that the main activity of people in the tent to carry out is to sleep, that is to say that the most important help the camping tent supporting is to protect the basic rest and sleep.

Analysis of the Physical Condition. In order to adapt to different environments, the physical and mental health of people will change under different natural conditions. Therefore, the group investigated the changes of people's sleep quality, food intake and other aspects after lived in tents for a time. Table 1 for the changes of people' body after lived in the tent for some time.

Table 1 Statistics of the physical condition changes

\begin{tabular}{|c|c|c|c|c|c|}
\hline Project & Sleep quality & Food intake & Weight & Mental & Health \\
\hline $\begin{array}{c}\text { Decrease } \\
\text { (Variation) }\end{array}$ & $65 \%$ & $27 \%$ & $32 \%$ & $64 \%$ & $21 \%$ \\
\hline $\begin{array}{c}\text { Basically } \\
\text { maintained }\end{array}$ & $31 \%$ & $68 \%$ & $66 \%$ & $31 \%$ & $76 \%$ \\
\hline $\begin{array}{c}\text { Increase } \\
\text { (Good) }\end{array}$ & $4 \%$ & $5 \%$ & $2 \%$ & $5 \%$ & $3 \%$ \\
\hline
\end{tabular}

As can be seen from the table 1, after a period of time in the tent, the body and mind will change and be in different levels. The performance will be sleep quality decline, mental deterioration, and increase in the number of times and so on. Sleep, 65\% people's sleep were affected, and the sleep time reduced, according to the interview, the general sleep time reduced by $1 \sim 2$ hours. The body, there are nearly $30 \%$ soldiers suffered different levels of appetite and weight loss, etc. As psychological aspect, there are more than $60 \%$ people feel in bad mood in the tent.

From the point of view of the physical and psychological changes, the tent cannot support better protect for people to rest. There is no doubt that an effective rest is a direct impact on the recovery. Sleep is the key link for the people to raise enough energy and to restore vitality. It's necessary to improve the ability to get enough sleep of tent. While the poor spirit is mainly because at night cannot rest well, emotions become depressed, anxious, or even lead to mental low-spirited.

In order to investigate the change of the people's body, the increase or decrease of the incidence of the disease after the tent of the people was analyzed statistically. Therefore, in order to further understand the prevalence of the disease, the research group made a further study on the type of illness, the cold, heat stroke and other common diseases of the questionnaire statistics, Fig. 2 for different types of diseases accounted for the proportion. 


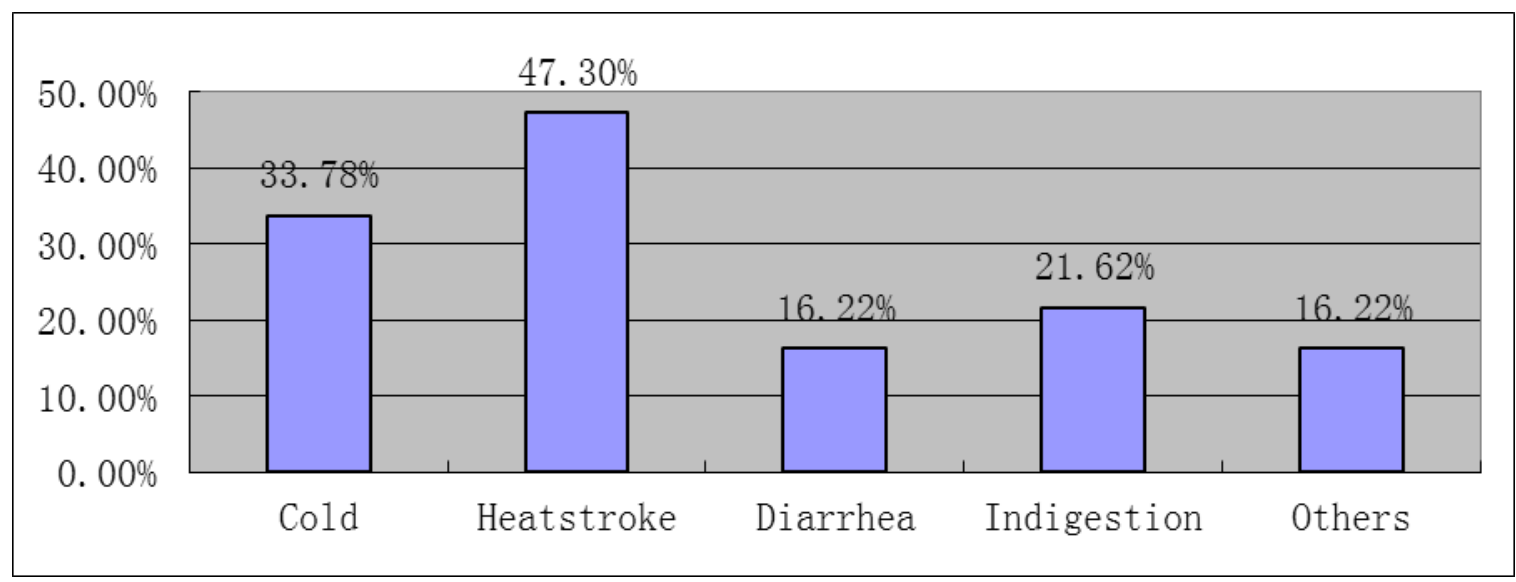

Figure 2. Disease types and proportion of people

It can be found from Fig. 2 that there are nearly half of people had symptoms of heatstroke, cold is in the second place, indigestion and diarrhea in third and fourth. According to interviews, the symptoms of heatstroke mostly caused by hot noon in the tent, and cold are caused by the big temperature difference between day and night in the tent.

The Analysis of the Environment inside the Tent. The evaluation parameters generally include camping conditions for the rest of the thermal environment, acoustic environment; good light environment and good air quality. Among them, whether the indoor environment comfortable is to a large extent depends on the indoor thermal environment. This section mainly aims at the investigation of the objective environment, the survey results can be seen in table 2 .

Table 2 Questionnaire of environmental factors in tent

\begin{tabular}{|l|l|l|l|l|l|l|}
\hline Project & $\begin{array}{l}\text { Cool } \\
\text { feeling }\end{array}$ & ventilation & $\begin{array}{l}\text { Dry } \\
\text { feeling }\end{array}$ & $\begin{array}{l}\text { Sound } \\
\text { insulation }\end{array}$ & $\begin{array}{l}\text { Daylight } \\
\text { environment }\end{array}$ & $\begin{array}{l}\text { Air } \\
\text { quality }\end{array}$ \\
\hline $\begin{array}{l}\text { Weak } \\
\text { (low-rank ) }\end{array}$ & $50 \%$ & $36 \%$ & $47 \%$ & $38 \%$ & $38 \%$ & $30 \%$ \\
\hline $\begin{array}{l}\text { Middle } \\
\text { rank }\end{array}$ & $49 \%$ & $62 \%$ & $31 \%$ & $49 \%$ & $53 \%$ & $55 \%$ \\
\hline $\begin{array}{l}\text { Strong } \\
\text { (high-rank) }\end{array}$ & $1 \%$ & $2 \%$ & $22 \%$ & $13 \%$ & $9 \%$ & $15 \%$ \\
\hline
\end{tabular}

Table 2 shows that the bad thermal environment of tent. Over half of the people think it very hot inside the tent, $98 \%$ of the people feel calm or only a slight wind, nearly half of the people felt damp in the tent. According to the interview, the reason is not only the hot and humid at noon difficult to rest, but also after midnight, a sharp decline in the temperature of the tent, the people are likely to be frozen to wake up in the northern area. This affects people's rest in a large extent; people in this environment would produce boredom, anxiety and other negative emotions, and even affect the physical and mental health if lived in tent for long-term. Because of the bad heat environment is the main tent tarpaulin poor insulation. In hot weather, the heat of the sun shine directly on the tent outside the tent with solar radiation, heat convection and wall conduction mode of heat absorption, the indoor temperature continues to rise, coupled with the internal ventilation quantity is not enough, the accumulation in the tent of the moisture is not circulation, together, in the tent "muggy" feeling very obviously [9].

Indoor air quality, noise and lighting conditions in the tent have a certain impact on the rest. Nearly $1 / 3$ of the people are not satisfied with these environmental factors, but more than half of the soldiers believe that the indoor air quality, noise, lighting and others affects the rest a little. Camping tent attribute requirements of portability, using thin fabric as a tarpaulin, windproof, rainproof, anti-mosquito characteristics, can be a relatively independent space for the security in the 
field of isolation [10]. Therefore, the quality of the air inside the tent, noise and lighting, are the important factors for upgrading camping tents.

Aspects of the Tent to Be Improved. The advantages and disadvantages of the tent environment influence the health to some extent. The current research on the improvement of the tent abroad is mainly focused on the optimization performance of cloth and tent structure improvement [15], but there is a little research makes people satisfaction in practice. In order to improve the tent usefully, the group makes an investigation on the aspects people mostly want to improve, the results shown in Fig. 3.

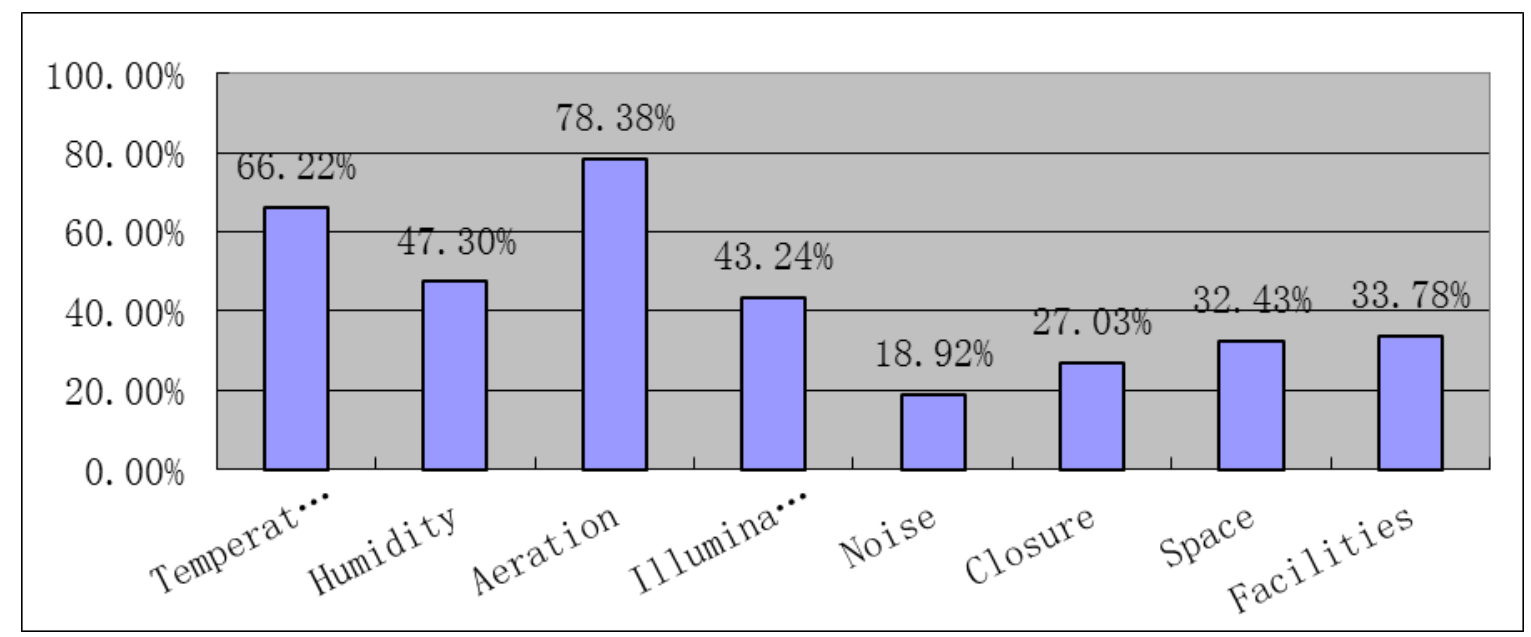

Figure 3. Statistics of the important aspect

Fig. 3 illustrates the tent environment needs to be improved in many aspects, tent thermal and humid environment ranks in the top three. They are ventilation, temperature and humidity. The above chart shows that the living condition of tent is far behind the fixed barracks. Indoor lighting, hardware facilities, maintenance of the structure of the tent needs to be improved. The analysis shows that the most needed improvement is the large temperature difference in the tent and the humid and hot environment.

\section{Summary}

During the period from May to July, people in the tent cannot get enough rest and the sleep generally reduces by 1 to 2 hours. There is a risk of varying degrees physical fatigue, mood irritability, lethargy and other conditions and a serious decline in immunity. Because of the close lax, the camping tent cannot guarantee a good health conditions and the dust virus is easy to enter.

The factors of camping tents such as hot and humid environment, lighting, Sound insulation, closure, facilities and space are all behind the fixed barracks. Air quality, light, noise and other factors are certain extent affects the people's rest; thermal and humid environment is bad. The hot and humid air at noon is the most important factor affecting the rest of the people. There is a great potential in improving or changing the tent environment.

\section{Reference}

[1] Ruinan an, Xiaofeng Yang, Chunlong Zhuang. Optimization and Simulation of Heating Supply for Military Tents [J]. Refrigeration and Air Conditioning, 2015,02:206-210+228

[2] Huaibin Gao, Guanghong Huang, Hongjun Li, Jun Li. Development and Selection of Tent Heating [J]. Building Energy\&Environment, 2015, 04:36-39.

[3] Yinfu Bai, Long Xu, Xingyu Liao, Long Enshen, Jing King, Ruhe Zhao. Natural Temperature Control Materials Energy Saver and Natural Ventflation in Night to Improve the Tent Thermal Environment [J]. Refrigeration and Air Conditioning, 2014, 05:556-559. 
[4] Xiaogang Wang. Different Porosity Tents Base Cloth [J]. SHANDONG FANGZHI KEJI, 2012, 05:53-56.

[5] Xiling Du. Canopy structure parameters on temperature and humidity effect of tent [D]. Supervisor: Guangyin Xie. Xi'an Polytechnic University, 2012.

[6] Tao Wang, Chen Hong. Research on Thermal Insulation Effect of Double-roof Tent [J]. BUILDING SCIENCE, 2010, 12:59-63.

[7] Wei Wang. A Research a Long-Span Gable Structure Post-Disaster Shelter [D]. Shenyang Construction University, 2012

[8] Shaohua Hu, Qinglin Meng, Wang Lin. Experimental study on the improvement of the thermal environment of the tent $[\mathrm{J}]$. Journal of Logistic Engineering University, 2007 (02): 81-83+87.

[9] Qinfang Wang, Bo Zhang, Lifang Wang. The Analysis of Fators Influncing Indoor Comfortability [J]. Contamination Control \& Air-conditioning Technology, 2012 (4): 74-76.

[10] Tao Wang. Research on Indoor Thermal and Humidity Environment and Simulation of Improvement Measures for Relief Tents [D]. Chongqing University, 2009 